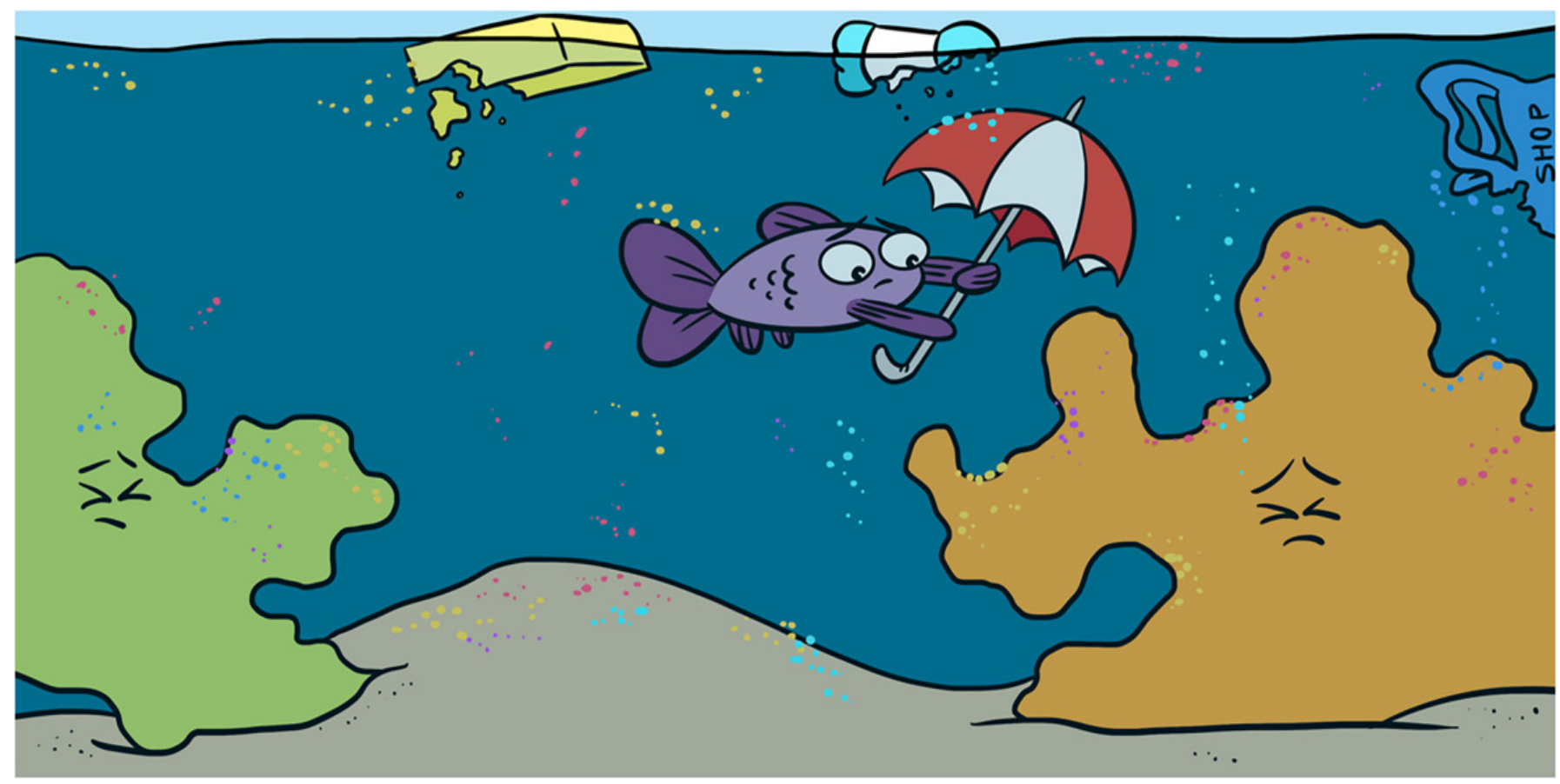

\title{
MICROPLASTICS: SMALL PARTICLES, BIG THREAT
}

\section{Silvia Arossa ", Cecilia Martin, Susann Rossbach and Carlos M. Duarte}

Biological and Environmental Science and Engineering Division (BESE), Red Sea Research Centre (RSRC) and Computational Bioscience Research Center (CBRC), King Abdullah University of Science and Technology (KAUST), Thuwal, Saudi Arabia

YOUNG REVIEWERS:

\begin{tabular}{|l} 
ESTELLE \\
AGE: 10 \\
ISTITUTO \\
COMPREN- \\
SIVO ALTA \\
VALDI SOLE \\
AGE: 12
\end{tabular}

You have probably heard that plastic pollution is becoming a big problem for the environment, and especially for the oceans. When a piece of plastic reaches the sea, the seawater and sunlight make it slowly fall apart into tiny plastic particles. These small particles are called microplastics and are even smaller than a ladybug-and sometimes not even visible. Scientists have found that many marine animals mistake these microplastics for food and eat them! But what about the animals in coral reefs? Many animals in reefs, including corals and giant clams, are fixed to the bottom of the sea and cannot move. So, they cannot escape from the microplastics that are literally "raining down" on them. Recently, we discovered that many of these coral reef animals are not only eating the microplastics, but the plastics can also stick on their bodies like flies on flypaper!

\section{WHAT ARE MICROPLASTICS?}

Think about how many plastic objects you use every day in your daily life-at home, at school, and even in your free time. Many plastic objects are used only for a few seconds and then thrown away. This is why more and more new plastic needs to be produced every day. 


\section{Figure 1}

Microplastics are formed in the oceans when sunlight, chemical reactions, waves, and water currents break down large plastic products, called macroplastics. The plastic pieces become smaller and smaller over time and are called microplastics when are smaller than $5 \mathrm{~mm}$ in diameter.

\section{MICROPLASTICS}

Tiny pieces of plastic smaller than $5 \mathrm{~mm}$ in diameter.

\section{WATER COLUMN}

The space occupied by seawater from the surface of the ocean to its bottom.

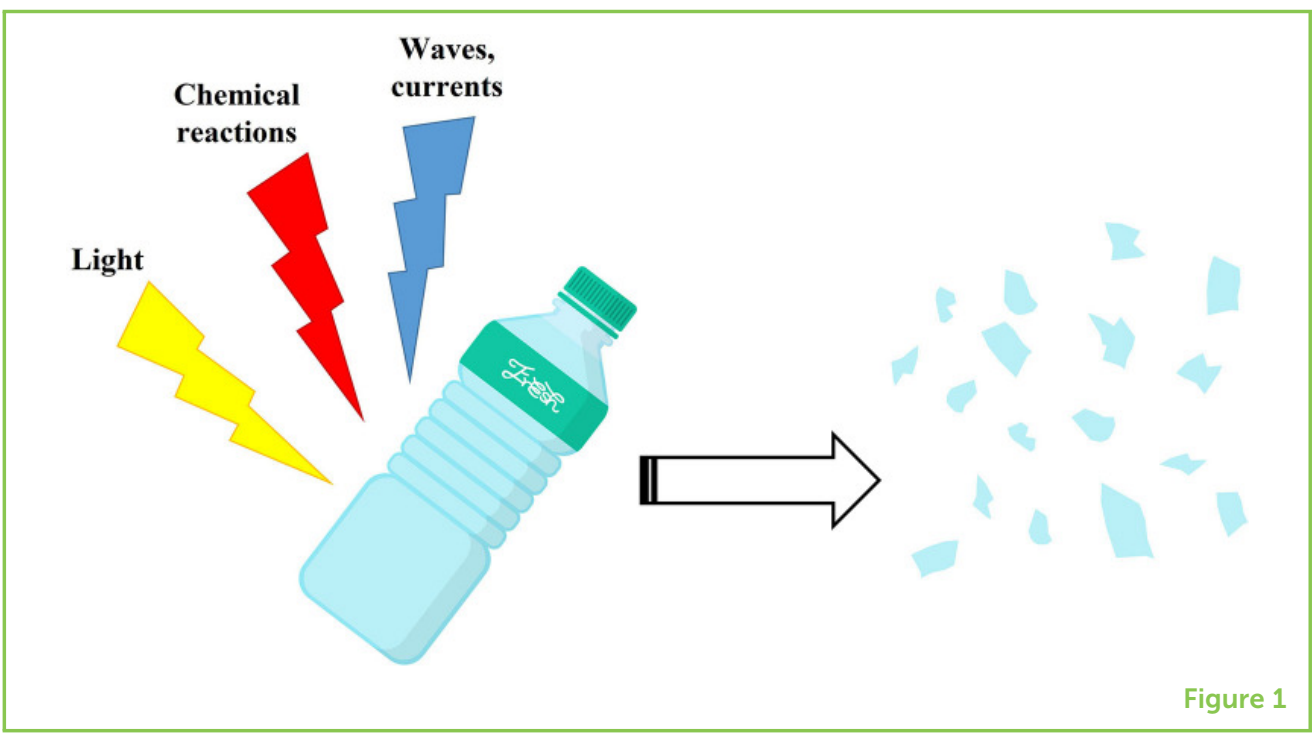

Worldwide, about 1,000,000 tons of plastic are produced every day. This equals about 1,000 trucks full of plastic bottles! What happens to a plastic bottle or to a pen after we stop using it? In most cities, recycling is a common practice and plastic is re-used to produce new objects. Unfortunately, recycling does not happen everywhere or to every plastic object. Pens and markers, for example, cannot be recycled because they contain ink. These objects end up in landfills. Sometimes, people do not follow the rules and dispose of plastics in the environment instead of the recycle bin. Consequently, these objects can be washed away by the rain, ending up in rivers and eventually in the ocean.

Did you know that, once it has reached the sea, a plastic bottle takes several 100 years to fully break down [1]? During this time, the plastic bottle can travel around the globe, transported by the water currents. On the way, the waves, currents, sunlight, and chemical reactions break down bottles and other large pieces of plastic trash (called macroplastics) into tiny plastic pieces, which are called microplastics (Figure 1) [2]. For some plastic trash, the transformation from macroplastic to microplastic can take up to 1,000 years! Some products that we use daily already contain microplastics, such as toothpastes, scrubs, and skincare products. These microplastics can be washed down the drain while we are showering or brushing our teeth, and eventually they can reach the oceans as well.

\section{WHY ARE MICROPLASTICS DANGEROUS FOR OUR OCEANS?}

Plastic particles are often believed to float on the surface of the ocean. This is true for light plastic pieces like the ones from bags and cups, but heavy microplastics, like those from some broken toys, sink in the water column and reach the bottom of the sea. So, plastic can be 
Figure 2

Bioaccumulation is the process by which toxic substances accumulate in organisms as they eat other organisms. For example, in the ocean, if one small fish eats one plastic particle and then two of these small fish are eaten by a medium-sized fish, the medium-sized fish has already taken up 2 particles. If two of the medium-sized fish are eaten by a bigger fish, that fish will have 4 particles in its body.

\section{FOOD WEB}

The different organisms, from tiny plants to whales and everything in between, that eat each other or that are eaten.

\section{BIOACCUMULATION}

Process by which toxic substances accumulate in organisms as they eat other organisms.

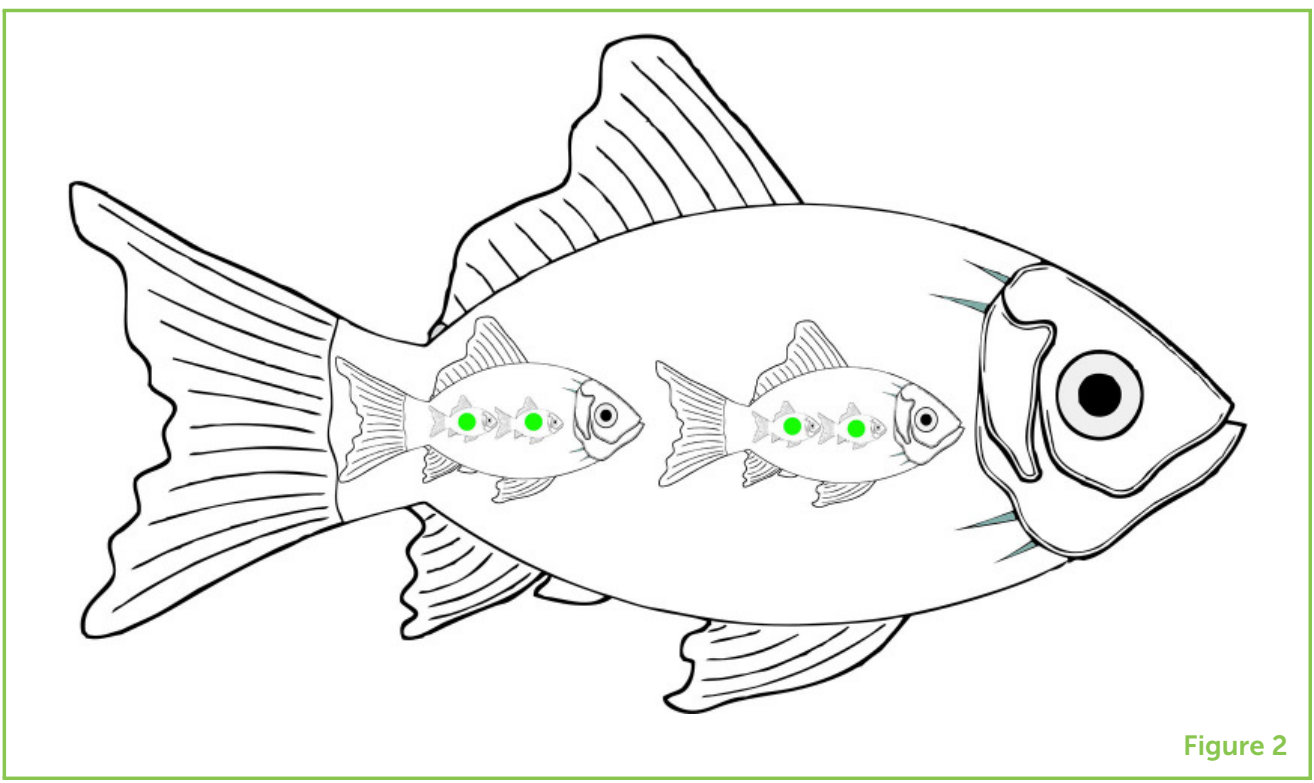

everywhere in the ocean! Plastic particles can be mistaken for food by some hungry marine animals, who then fill their stomachs with plastic instead of real food. This is true for both macro- and microplastics, but the smaller the plastic pieces are, the more likely they are to be eaten and enter the food web. Just imagine a small fish that eats microplastics by mistake. If a bigger fish now eats a few of these smaller fish, it takes up the microplastics that were inside the smaller fish. The bigger fish has then already multiplied the amount of plastics inside its body. If this eating and being eaten goes on, more and more plastic ends up in some predator animals [3]. This is called bioaccumulation (Figure 2).

Scientists have observed that eating microplastics can lead to health problems in many marine animals. For example, sometimes plastic particles are very sharp and can injure the stomach or digestive system. Also, when their stomachs are filled with plastics, animals do not feel hungry and do not eat proper food, so they end up starving! Plastic particles can also act like little sponges that soak up chemicals, especially when the particles travel through the oceans for a long time. When these chemical-soaked plastics are eaten by marine animals, or even by humans, the chemicals can cause a lot of health problems, such as inability to reproduce.

\section{MICROPLASTICS IN CORAL REEFS}

Although scientists investigating plastic pollution knew that a lot of plastic waste was ending up in the Red Sea, they were only able to find a little of it floating on the surface or suspended in the water column. They wondered where all the missing plastic went! One possibility is that plastic particles are "raining down" on coral reefs and getting trapped there [4]. 
Figure 3

(A) Corals have tiny polyps that live inside the hard skeleton and catch food particles in the water with their tentacles. (B) Giant clams also capture food particles from the water, by filtering it. $(C, D)$ Scientists added fluorescent green plastic particles into aquaria containing corals or giant clams. $(\mathrm{E}, \mathrm{F})$ Lots of plastic particles stuck to the skeletons of the corals and the shells of the giant clams.

\section{ECOSYSTEM}

All the living and non-living things in an area, including plants, animals, small organisms, water, soil, and rocks.

\section{POLYPS}

Tiny organisms that live inside a coral and are responsible of the creation of its skeleton
A

B

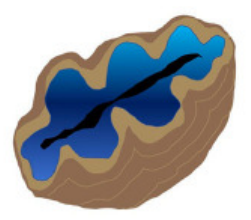

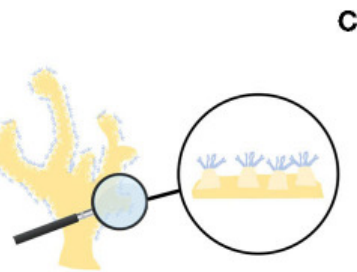

C

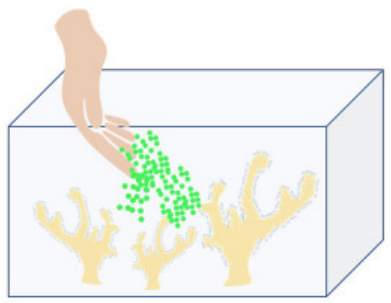

D

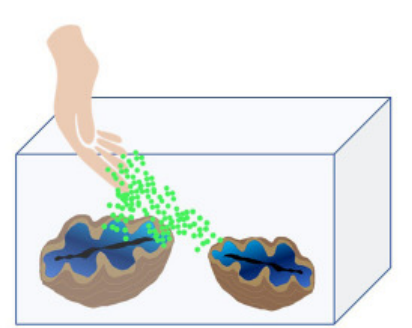

E

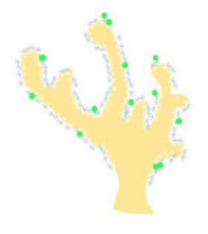

$\mathbf{F}$

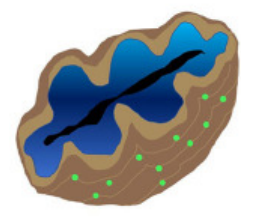

Figure 3

Coral reefs are very important ecosystems, because they provide protection and food for many other organisms that call the reef their home. What makes coral reefs special is that their structure is built by the hard skeletons of the corals, which are the parts of the corals that we usually see. Besides corals, there are other important animals found in coral reefs, including giant clams. These are very big clams that usually live anchored between the corals (Figure 3B). Giant clams get food by sucking water into their mouths and eating all the tiny particles that are floating in the water. Corals can also catch those tiny particles from the water, using the tentacles on their polyps, which are the living part of the coral that sits inside the skeleton (Figure 3A). As both corals and giant clams are permanently attached to the ocean floor, they must wait for food particles to pass by, like the conveyor belt in a sushi restaurant. They also cannot move to escape the plastics that are raining down on them in the water.

\section{EXPERIMENTS ON CORALS AND GIANT CLAMS}

Scientists wanted to see how corals and giant clams interact with the plastic particles in the water. Various corals and giant clams were collected from the Red Sea and placed into aquaria. Green fluorescent microplastics, which glow bright green so that they are easy to see, were added into the water (Figures 3C,D). The experiment on corals lasted for 24-28 h and the one on clams lasted for 12 days. At the end of the experiment, using a microscope, scientists counted the microplastic pieces found inside the animals' stomachs and attached to the outsides of their bodies (on the coral skeletons or on the clam shells). They found that each coral piece ate 80 plastic particles every day (1-2 microplastic particles for every 10 polyps), and each giant clam ate 8 plastic particles every day. The real surprise was that thousands of microplastic particles were found attached to the 


\section{ADHESION}

Process of particle attachment onto a surface.

\section{CALCIFIER}

Organism that uses calcium carbonate (the same materials of our bones) to create its skeleton. surfaces of corals and giant clams (Figures 3E,F). The amount of microplastics stuck to the skeletons of the corals (a process called adhesion) was 40 -fold higher than the amount the corals ate. The giant clams had 60 times more plastics stuck to their shells than inside their bodies! This was the first evidence that adhesion of plastic particles to ocean organisms is so strong $[5,6]$ !

\section{WHY IS THIS STUCK PLASTIC A PROBLEM?}

The finding that the plastic particles can get stuck to the surface of corals or to the shells of giant clams is really important for a number of reasons. First, since corals and clams are calcifiers (which means they make their own skeletons and shells out of a substance called calcium carbonate), the trapped microplastics can be built into their skeletons or shells. This could make the structure of the entire reef weaker or lead to health problems for the corals and clams. Second, coral skeletons and clam shells are often homes for other organisms like small fishes, shrimps, worms, or tiny algae. All these organisms could then more easily come into contact with the potentially harmful plastics that are stuck to the surfaces of clams and corals. Last but not least, the large amount of microplastics that the scientists found attached to the reef structures explains why they did not find as much plastic as expected in the waters of the Red Sea-this sea has one of the most extensive coral reef systems in the world.

Scientists hope that this study will help everyone to understand the negative impact that plastic has on all marine organisms and why it is important to reduce the amount of plastic that reaches the oceans. Anyone can help with this! For example, we can choose reusable objects over single-use plastics: think about shopping bags, water bottles and cups. When this is not possible, we should always dispose of plastic trash in the correct bin, for recycling. If we all chip in to reduce the use of plastics and properly dispose of them, we can help to protect our oceans and the animals living there from the big threat posed by these tiny plastic particles.

\section{ORIGINAL SOURCE ARTICLE}

Arossa, S., Martin, C., Rossbach, S., and Duarte, C.M., 2019. Microplastic removal by Red Sea giant clam (Tridacna maxima). Environ Pollut. 252:1257-66. doi: 10.1016/j.envpol.2019.05.149

\section{REFERENCES}

1. Ioakeimidis, C., Fotopoulou, K. N., Karapanagioti, H. K., Geraga, M., Zeri, C., Papathanassiou, E., et al. 2016. The degradation potential of PET bottles in the marine environment: an ATR-FTIR based approach. Sci. Rep. 6:23501. doi: $10.1038 /$ srep23501 
2. Barnes, D. K., Galgani, F., Thompson, R. C., and Barlaz, M. 2009. Accumulation and fragmentation of plastic debris in global environments. Philos Trans $R$ Soc Lond B Biol Sci. 364:1985-98. doi: 10.1098/rstb.2008.0205

3. von Moos, N., Burkhardt-Holm, P., and Köhler, A. 2012. Uptake and effects of microplastics on cells and tissue of the blue mussel Mytilus edulis L. after an experimental exposure. Environ Sci Technol. 46:11327-35. doi: 10.1021/ es302332w

4. Martí, E., Martin, C., Cózar, A., and Duarte, C. M. 2017. Low abundance of plastic fragments in the surface waters of the red sea. Front. Mar. Sci. 4:333. doi: 10.3389/fmars.2017.00333

5. Arossa, S., Martin, C., Rossbach, S., and Duarte, C. M. 2019. Microplastic removal by Red Sea giant clam (Tridacna maxima). Environ Pollut. 252:1257-66. doi: 10.1016/j.envpol.2019.05.149

6. Martin, C., Corona, E., Mahadik, G. A., and Duarte, C. M. 2019. Adhesion to coral surface as a potential sink for marine microplastics. Environ. Pollut. 255:113281. doi: 10.1016/j.envpol.2019.113281

SUBMITTED: 21 September 2020; ACCEPTED: 25 November 2021; PUBLISHED ONLINE: 17 December 2021.

EDITED BY: Christian Robert Voolstra, University of Konstanz, Germany

CITATION: Arossa S, Martin C, Rossbach S and Duarte CM (2021) Microplastics: Small Particles, Big Threat. Front. Young Minds 9:608621. doi: 10.3389/frym.2021. 608621

CONFLICT OF INTEREST: The authors declare that the research was conducted in the absence of any commercial or financial relationships that could be construed as a potential conflict of interest.

COPYRIGHT () 2021 Arossa, Martin, Rossbach and Duarte. This is an open-access article distributed under the terms of the Creative Commons Attribution License (CC BY). The use, distribution or reproduction in other forums is permitted, provided the original author(s) and the copyright owner(s) are credited and that the original publication in this journal is cited, in accordance with accepted academic practice. No use, distribution or reproduction is permitted which does not comply with these terms.

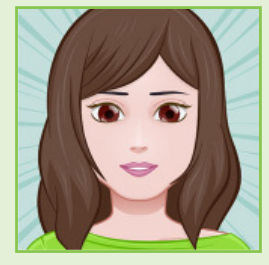

\section{YOUNG REVIEWERS}

\section{ESTELLE, AGE: 10}

Estelle is an adventurous spirit who has a wide variety of interests from dance and make-up to filthy experiments and baseball. She loves to write and once even had a poem published in an online journal. Estelle loves hanging out with friends just as much as she loves to annoy her little brother and sister. She lives with her family in the Northeast where she gets to swim in the ocean during summer and go skiing and sledding in the winter. 

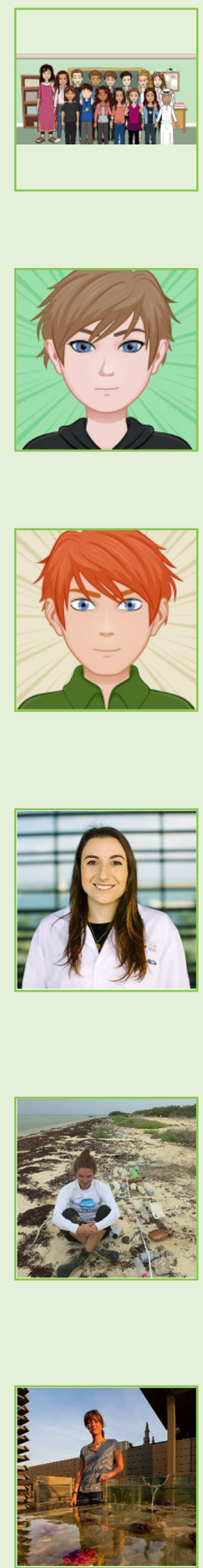

\section{ISTITUTO COMPRENSIVO ALTA VAL DI SOLE, AGE: 12}

We are a small class going to a school in the middle of the Alps in Italy and have just entered secondary school and enjoy almost all the subjects! We were honored to have been reviewers of the article that let us understand the big problem that concern plastic in the oceans. We will do our best to keep this planet clean from plastic!

\section{JULIA, AGE: 10}

Julia is a 5th grader and enjoyes learning about the environment! She loves animals and is interested in every little fact about them. She loves music and plays the piano, the drums, the viola and helps mom figuring out the bass tab of her favorite songs. Julia also loves drawing and learning about science. She wrote a fiction book and loves her dog.

\section{MARCO, AGE: 10}

Marco is a 10 year old boy who loves adventures and nature. He recently developed a passion for soccer and he walks across town to go practice with his friends. Marco has a wonderful voice and he loves singing.

\section{AUTHORS}

\section{SILVIA AROSSA}

Silvia is a Ph.D., candidate at the King Abdullah University of Science and Technology. She started her journey into the fascinating underwater world by studying sea turtles and sea anemones, then she has gradually become interested in understanding how human activities can influence marine organisms. Nowadays, she is investigating how climate and environmental changes may affect marine vertebrates, invertebrates and even human cells. *silvia.arossa@kaust.edu.sa

\section{CECILIA MARTIN}

Cecilia is a marine scientist that started to study the marine world diving through the coral reefs of the Maldives. Now she lives on the coast of the Red Sea, where she is monitoring the plastic pollution that ends up there. She is trying to understand how much plastic is dumped every day in the Red Sea and where this can be found. She is looking for plastic in the coral reefs, but also in the water, on the beaches, on the seafloor, and in the mangroves (plants living between the sea and the shore).

\section{SUSANN ROSSBACH}

Susann is a marine researcher that wants to understand how marine animals, such as giant clams and corals, are building their skeletons. She is especially interested in learning how they can survive in the changing conditions of our oceans. She loves to dive, explore the underwater world and share the lessons she learns and pictures she takes underwater with others. 


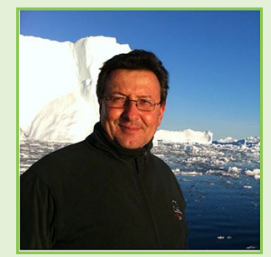

\section{CARLOS M. DUARTE}

Carlos is a marine researcher that, after nearly four decades documenting how human pressures impacts on marine life, wants to drive, from science, a global effort to rebuild the abundance of marine life. He loves dogs and enjoys being away in the open sea, reading, swimming, snorkeling, walking, and playing with his grandson Oliver. 